

\section{Sumário}

Dossiê TEMÁTICO: NOVOS INSTITUTOS JURÍDICOS DE LICITAÇÕES E CONTRATOS 17

I. LicitaÇõEs E CONTRATOS PÚBLICOS: PARTE GERAL. 18

INTEGRATED CONTRACT IN LAW 14.133/2021: NEW LAW, SAME PROBLEMS? A STUDY OF COMPARATIVE LAW .20

Paulo Afonso Cavichioli Carmona, Bruno Ribeiro Marques e Odilon Cavallari

Reajustamento de preços na Nova Lei de Licitações e Contratos Administrativos BRASILEIRA: O "Princípio" Da ANUALIDAde.

Ricardo Silveira Ribeiro e Bráulio Gomes Mendes Diniz

A nova Lei de Licitações, as encomendas tecnológicas e o diálogo competitivo .61 André Dias Fernandes e Débora de Oliveira Coutinho

LiCITAÇÕES, CONTRATOS E O IMPULSO À APRENDIZAGEM PROFISSIONAL: UM ESTUDO SOBRE A CONTRATAÇÃo de APRENDizes no ESTAdo do AMAZONAS, BRAsIL

Emerson Victor Hugo Costa de Sá, Natasha Yasmine Castelo Branco Donadon e Mauro Augusto Ponce de Leão Braga

Licitações, contratos e Modelo Brasileiro de Processo: notas sobre a viabilidade DA UTILIZAÇÃo DE FERRAMENTAS PROCESSUAIS PARA CONFERIR MAIOR EFICIÊNCIA ÀS AQUISIÇÕES PÚBLICAS

Claudio Madureira e Carlos André Luís Araujo

RESOlUÇão DE CONFLITOS COM A ADMINISTRAÇÃo PÚBLICA E A NOVA LEI DE LICITAÇÕES E CONTRATOS: REFORÇO DOS MEIOS ALTERNATIVOS.

Clarissa Sampaio Silva e Danille Maia Cruz

A Adesão do Brasil ao Acordo sobre Contratações Públicas da OMC: entre tabus e DIFICULDADES REAIS

Eduardo Ferreira Jordã e Luiz Filippe Esteves Cunha

II. Accountability e controle

A LEI N. ${ }^{\circ}$ 14.133/2021 E OS NOVOS LIMITES do CONTROLE EXTERNO: A NECESSÁRIA DEFERÊNCIA dos Tribunais de Contas em prol da Administração Pública .................................. 162 Ricardo Schneider Rodrigues

O CONTROLE DAS CONTRATAÇÕES PÚBliCAS E A NOVA LEI DE LICITAÇÕES: O QUE HÁ DE Novo? 183

Leandro Sarai, Flávio Garcia Cabral e Cristiane Rodrigues Iwakura 
Programa de compliance como exigênCia em licitações: ANálises EM Prol da QUALIFICAÇÃo DO PROCESSO LICITATÓRIO NO CONTEXTO DA LEI 14.133/2021.

Cristian Ricardo Wittmann e Anayara Fantinel Pedroso

A NOVA REALIDAde bRASILEIRA DE NECESSIDADE DE PROGRAMAS DE INTEGRIDADE DAS PESSOAS JURÍDICAS LICITANTES EM PROCESSOS LICITATÓRIOS DA ADMINISTRAÇÃO PÚBLICA 227

Fernando Silva Moreira dos Santos e Luiz Fernando de Oriani e Paulillo

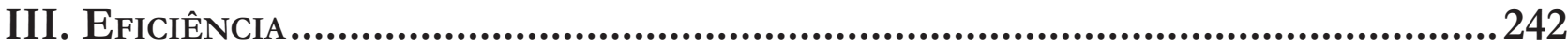

Efficiency contracts in the New Brazilian Procurement Law: conceptual FRAMEWORK AND INTERNATIONAL EXPERIENCE

Floriano de Azevedo Marques Neto, Hendrick Pinheiro e Tamara Cukiert

A gestão de riscos como instrumento para a aplicação efetiva do Princípio Constitucional dA EFICIÊNCIA.

Rafael Rabelo Nunes, Marcela Teixeira Batista Sidrim Perini e Inácio Emiliano Melo Mourão Pinto

IV. Contratação PÚblica No Direito ESTrangeiro

LA ADQUisición de VACUNAS CONTRA LA COVID-19 POR COLOMBIA: ENTRE LA CONFIDENCIALIDAD Y LA FALTA DE TRANSPARENCIA. 284

Gressy Kareny Rojas Cardona e David Mendieta

LA DISCRIMINACIÓN EX POST DE LOS OFERENTES DE UNA LICITACIÓN PÚBLICA COMO INFRACCIÓN ADMINISTRATIVA Y DE LIBRE COMPETÊNCIA 312 Jaime Arancibia Mattar

LA DISCRIMINACIÓN EX POST DE LOS OFERENTES DE UNA LICITACIÓN PÚBLICA COMO INFRACCIÓN ADMINISTRATIVA Y DE LIBRE COMPETÊNCIA..........................................................332 Udochukwu Uneke Alo, Obiamaka Adaeze Nwobu e Alex Adegboye

Outros Temas 348

I. Políticas públicas e institucionalidade

¿Existe El derecho humano a la identidad Cultural de los Migrantes en El Derecho INTERNACIONAL? 351 Juan Jorge Faundes e Glorimar Alejandra Leon Silva

El acceso a la justicia y el debido proceso ante el Tribunal Constitucional y la CorTe Suprema: dos NOCIONES DEL CONTENCIOSO ADMINISTRATIVO CHILENO .384 Pedro Harris Moya 
“Ministrocracia” E DECISÕES INDIVIDUAis CONTRAditórias No Supremo Tribunal FEDERAI

Ulisses Levy Silvério dos Reis e Emilio Peluso Neder Meyer

A POlÍtica de INOVAÇÃo COMO INSTRUMENTO DE REDUÇÃo DAS DESIGUALDADES REGIONAIS NO BRASIL

Caroline Viriato Memória e Uinie Caminha

Conflitos de Competência E A JudicializaÇão da Saúde no Federalismo Brasileiro.447 Jorge Leal Hanai, Luis Antônio Abrantes e Luiz Ismael Pereira

O Ministério Público no enfrentamento dos Reflexos da CRise da Covid-19: UMA

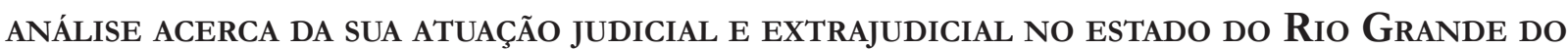
NorTE

Raquel Maria da Costa Silveira, Ana Mônica Medeiros Ferreira, Flávio Luiz Carneiro Cavalcanti e Haroldo Helinski Holanda

A CONSAgRaÇão CONSTITUCIONAL DA POlítica FALIMENTAR

Nuno de Oliveira Fernandes

II. Políticas públicas, grupos vulneráveis e litígios estruturais

LAS LIMITACIONES A LOS DERECHOS DE LOS GRUPOS VULNERABLES Y LOS SUJETOS DE ESPECIAL PROTECCIÓN DURANTE LA PANDEMIA Mary Luz Tobón Tobón

LitígIOS ESTRUTURAIS E A PROTEÇÃO DOS DIREITOS DOS POVOS INDÍGENAS DURANTE A PANDEMIA DE Covid-19: CONTRIBUições do ICCAL

Ana Carolina Lopes Olsen e Bianca M. Schneider van der Broocke

EPISTEMICÍDIO DAS NARRATIVAS NEGRAS E LITÍGIO ESTRUTURAL: INSTRUMENTOS EXTRAJUDICIAIS PARA DISSOLUÇÃO DO PROBLEMA NO SISTEMA EDUCACIONAL .......................................582

Vitor Fonsêca e Caroline da Silva Soares

Trajetórias E DiRETRIZES dAS POlíticas PÚbliCAS NACIONAIS PARA A POPULAÇão INFANTOJUVENIL EM SITUAÇÃO DE RUA...

Wânia Cláudia Gomes Di Lorenzo Lima, Cynthia Xavier de Carvalho e Maria Creusa de A. Borges

Emprendimiento como Fuente de Ingresos para las Víctimas del Conflicto Armado en el Marco de la Ley 1448 de Colombia. Reflexiones de la Implementación en el Valle del Cauca

Saulo Bravo García e Luz Marina Restrepo García

III. Políticas públicas e aÇão Restaurativa. 
JUSTIÇA RESTAURATIVA COMO AÇÃO COMUNICATIVA: EQUILÍBRIO ENTRE SISTEMA E MUNDO DA

Daniela Carvalho Almeida da Costa e Luciana Leonardo Ribeiro Silva de Araújo

JUSTIÇA RESTAURATIVA: ACORDOS E COOPERAÇÃO.................................................668

Samyle Regina Matos Oliveira e Selma Pereira de Santana 


\title{
Emprendimiento como Fuente de Ingresos para las Víctimas del Conflicto Armado en el Marco de la Ley 1448 de Colombia. Reflexiones de la Implementación en el Valle del Cauca*
}

\author{
Entrepreneurship as a Source of Income \\ for the Victims of the Armed Conflict Under \\ Law 1448 of Colombia. Reflections on the \\ Implementation in the Valle del Cauca
}

\author{
Saulo Bravo García** \\ Luz Marina Restrepo García***
}

\section{Resumen}

El objetivo de este estudio consiste en analizar como la falta de articulación interinstitucional y la decisión por emprender tienen un efecto sobre la fuente de ingresos y el equilibrio económico durante el periodo 2017 - 2019 para las víctimas del conflicto armado en el marco de la ley 1448 de 2011 en el Valle del Cauca. Para cumplir dicho objetivo, se empleó una metodología, que se concentró en tres etapas. La primera de ellas se relaciona con la definición del tema de investigación incorporado dentro de los pasos lógicos y partes claves que conforman el anteproyecto. Posteriormente, se definió la ruta que condujera a los resultados del análisis de este estudio y en este sentido, se buscó el soporte teórico, en el que se definieron los pasos y los instrumentos para la toma de la información. Se pudo verificar que la falta de articulación interinstitucional dificulta que los emprendedores, víctimas del conflicto armado, obtengan ingresos sostenibles y que con su actividad no logran un equilibrio económico.

Palabras clave: gestión pública; reparación integral; víctima del conflicto armado; generación de ingresos; emprendimiento.

Recebido em 06/06/2021

Aprovado em 22/11/2021

** Doctor en Administración de Empresas y Diploma de Estudios Avanzados de la Universidad de Sevilla.

E-mail: sbravo@usc.edu.co

*** Magister en Gestión Pública de la Universidad Santiago de Cali.

E-mail: luz.restrepo01@yahoo.com

\section{Abstract}

The aim of this study is to analyze how the lack of inter-institutional articulation and the decision to undertake to have an effect on the source of income and economic balance during the period 2017 - 2019 for victims of the armed conflict in the framework of Law 1448 of 2011 in Valle del Cauca. To meet this objective, a methodology was used, which focused on three stages. The first one is related to the definition of the research topic incorporated within the logical steps and key parts that make up the preliminary project. Subsequently, the route that led to the results of the analysis of this study 
was defined and in this sense, the theoretical support was sought, in which the steps and instruments for collecting the information were defined. It was found that the lack of inter-institutional articulation makes it difficult for entrepreneurs, victims of the armed conflict, to obtain sustainable income and that with their activity they do not achieve an economic balance.

Keywords: public management; comprehensive reparation; victim of the armed conflict; income generation; entrepreneurship.

\section{Introducción}

Con la vigencia de la Ley 1448 de 2011, el Estado colombiano crea la Unidad de Víctimas con el objetivo que coordine todas las acciones necesarias para reparar de manera integral y satisfactoria a las víctimas del conflicto armado.

Cuando una persona considera que se le han vulnerado sus derechos en marco del conflicto armado, el Estado por medio de las entidades públicas como las personerías, defensorías o la misma Unidad de Víctimas, les recibe su declaración de los hechos con el fin de evaluar y determinar si efectivamente se le reconoce como víctima. En caso de que el reconocimiento sea afirmativo, se inicia un proceso de reparación ya sea de manera individual o colectiva en componentes como ayuda humanitaria, salud, educación, vivienda, generación de ingresos, entre otros. De acuerdo a los componentes que se deben reparar en cada persona, la Unidad de Víctimas articula para que las instituciones converjan con el fin de realizar las acciones de acuerdo a su alcance y competencia. ${ }^{1}$

Para este artículo se enfocará el análisis en el componente generación de ingresos, donde intervienen entidades como el Ministerio de Trabajo, el Sena, Prosperidad Social, Alcaldías Municipales, Gobernaciones, Ministerio de Agricultura, Cajas de Compensación, ONG's, entre otros.

Es fuerte el impacto que se ha generado desde la crisis que ha surgido por el conflicto armado en Colombia, el problema que se planteó en este caso es como la falta de articulación interinstitucional dificulta que los emprendedores, víctimas del conflicto armado, tengan una fuente de generación de ingresos sostenible en el tiempo.

Desde donde se han presentado alternativas a la población de sostenibilidad considerando como principal elemento una fuente de generación de ingresos que conduzca a una estabilización socioeconómica, por lo que se consideraron dos formas opcionales de ingreso que son la vinculación laboral y el emprendimiento. Sin embargo, los tiempos de respuesta por parte del Estado, no han sido ajustados a la realidad de las necesidades que presentan las víctimas.

Existen entidades determinadas que hacen esfuerzos en función de la disminución de la problemática planteada, pero su capacidad no se ve suficiente en la demanda de personas afectadas en el conflicto, dentro de estas instituciones el Sena tiene establecida una ruta de atención con enfoque diferencial que parte de la Orientación Ocupacional y a partir de allí se les brinda formación ajustada a sus requerimientos, servicio público de empleo a través de la Agencia Pública de Empleo y asesoría en emprendimiento. En el aspecto de vinculación laboral, sirve como puente entre las empresas que buscan cubrir una vacante y el buscador de empleo. En cuanto a emprendimiento, su alcance llega hasta brindarle asesoría para la elaboración de un

\footnotetext{
1 OLAYA GOEZ, Paula Andrea. Proceso de Individuación y Subjetivación de Cinco Mujeres que llegan a Cali en medio del conflicto armado. 2014. Disertación (Maestría en Sociología) - Facultad de Ciencias Sociales y Económicas, Universidad del Valle, Cali, 2014. Disponible en: http://bibliotecadigital.univalle.edu.co/bitstream/10893/7585/1/0508699-p-14-ms.pdf.
} 
plan de negocios y buscar fuentes de financiación. Los entes territoriales como las Alcaldías y las Gobernaciones también realizan esta función ${ }^{2}$.

Entidades como Prosperidad Social, Ministerio de Agricultura y los entes territoriales, realizan programas de empleabilidad, con el fin de atender este componente que en ocasiones da una solución de ingresos a la población pero en otras ocasiones se doblan los esfuerzos institucionales de manera innecesaria donde se pierde la efectividad de los programas, por lo que se hace necesario que las estrategias establecidas desde la política de Estado permitan generar resultados en etapas tempranas con el fin de mejorar la calidad de vida a las víctimas del conflicto armado y dando cumplimiento con la ley 1448 de 2011 donde se estipula en el componente de generación de ingresos que comprende vinculación laboral y el emprendimiento como opción para la fuente de generación de ingresos. No obstante estos lineamientos requieren de seguimiento en los procesos de implementación que permitan retroalimentar actividades en función de la reparación integral y la influencia de proyectos generadores de ingresos y reparación, por tanto, esta investigación se enfocará en el análisis del emprendimiento como fuente de ingresos durante el período 2017 - 2019 para las víctimas del conflicto armado en el marco de la ley 1448 de 2011 en el Valle del Cauca, cuyo propósito intentará demostrar cuáles han sido los resultados y su eficiencia en la implementación dentro del proceso de reparación integral.

Por lo anterior, el documento se ordena de la siguiente manera: en primer lugar, se presenta un análisis previo sobre la literatura científica que permitió visualizar la aproximación conceptual de lo que es la política pública enfocada la ley de víctimas y sus implicaciones en el emprendimiento como fuente de generación de ingresos. En este apartado se muestran, además, las características de la ley describiendo sus opciones enfocadas al desarrollo del emprendedor; en segundo lugar, se plantea la metodología e hipótesis empleadas durante el estudio; en tercer lugar, se presentan los principales resultados, comprobación de las hipótesis, finalmente su discusión y conclusiones del estudio.

\section{Generalidades de políticas públicas}

\subsection{Conceptos y enfoques}

El término políticas públicas se describe según la literatura como un conjunto de objetivos, decisiones y acciones que aplican los gobiernos como parámetro para la solución de problemas en los ciudadanos incluyéndose él mismo en el momento de tomar una decisión pública ${ }^{3}{ }^{4}$. Es un arte porque se determina en la gestión dicotómica de los líderes en actividades de cumplimiento público, quienes deben tomar decisiones de desarrollo en etapas de políticas públicas y se puede visualizar como ciencia por el proceso de aplicación en las diferentes actividades que redundan en la ejecución pública ${ }^{5}$. El Estado cuenta con una estructura organizacional denominada administración pública conformada por una estructura orgánica compuesta por diversos organismos que sirven como entes facilitadores en soluciones al bienestar social y el control al desarrollo de proyectos y programas enfocados en mejorar el aspecto social de las comunidades partiendo del contexto parametrizado en las políticas públicas, esta genera sostenibilidad y equilibrio disciplinario de

\footnotetext{
2 CONGRESO DE COLOMBIA. Ley 448 de 2011: Artículo 51 y 130, de 10 de junio, por la cual se dictan medidas de atención, asistencia y reparación integral a las víctimas del conflicto armado interno y se dictan otras disposiciones. 10 de junio de 2011. Disponible en: https://www.unidadvictimas.gov.co/es/ley-1448-de-2011/13653.

3 TAMAYO SÁEZ, Manuel. El análisis de las políticas públicas. In: BAÑÓN, Rafael; CARRILLO, Ernesto. La nueva administración pública. Madrid: Alianza Editorial, 1997. p. 281-311. Disponible en: https://www.fundacionhenrydunant.org/images/stories/biblioteca/Politicas-Publicas/tamayo_analisis_de_polit_publ.tif.pdf.

${ }^{4}$ KITZMUELLER, Markus; SHIMSHACK, Jay. Economic Perspectives on Corporate Social Responsibility. Journal of Economic Literature, v. 50, n. 1, p. 51-84, 2012. Disponible en: doi:10.1257/jel.50.1.51.

5 VARGAS ARÉBALO, Cidar. Análisis de las políticas públicas. Perspectivas, v. 19 p. 127-136, ene./jun. 2007. Disponible en: https:// www.redalyc.org/pdf/4259/425942453011.pdf.
} 
conducta social en una nación ${ }^{6}$, en un análisis conceptual concluyen que para detectar la buena aplicación de las políticas públicas, se requiere un riguroso seguimiento que evalúe su eficiencia ${ }^{7}$, mientras que, por su lado en un estudio de la misma característica determina que la rendición de cuentas debe comprenderse no sólo en su dimensión político-administrativa, sino como un elemento de gestión en el manejo de los fondos públicos $^{8}$, lo que indica que la evaluación debe involucrar un enfoque metodológico y técnicas con rigor y tratamiento científico en el tratamiento de revisión y ejecución gubernamental ${ }^{9}$. De igual forma, se evidencian a las articulaciones de gobierno de trabajo en red como un sistema a través del cual las participaciones de actores cumplen funciones ${ }^{10} \mathrm{y}$ se incluyen en actividades de función pública convirtiéndose en un elemento fundamental en el ámbito democrático ${ }^{11}$.

Asimismo, se emplean las políticas basadas en evidencia, las cuales desempeñan un papel importante en la mejora y desarrollo de las políticas ${ }^{12},{ }^{13}$, como también, existen unas prácticas enfocadas en el seguimiento y evaluación de las políticas públicas ${ }^{14}$.

Gráfico 1 - Sinergia en función de la construcción y aplicación de la política pública

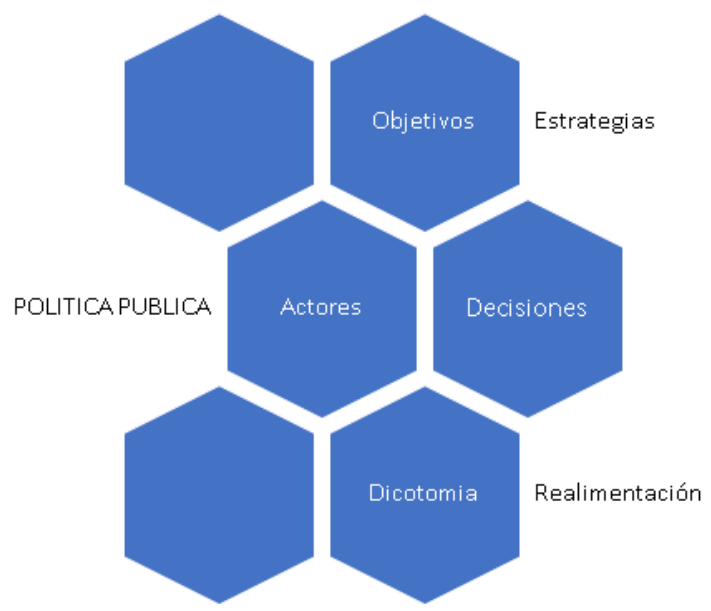

Fuente: elaboración propia.

\footnotetext{
${ }^{6}$ PINILLA, Jaime; GARCÍA-ALTÉS, Anna. La evaluación de políticas públicas: Informe SESPAS 2010. Gaceta sanitária, v. 24, p. 114-119, dic. 2010. Disponible en: https://www.sciencedirect.com/science/article/pii/S021391111000169X.

7 MONDRAGÓN, Jaione. La evaluación de los programas públicos: objeto, contenido y aplicación de diferentes instrumentos para la evaluación. In: BAÑÓN, R. (ed.). La evaluación de la acción y de las políticas públicas. Díaz de Santos, 2003. p. 3-12. Disponible en: https://books.google.com.co/books?hl=en\&lr=\&id=9QE4SRJV-HUC\&oi=fnd\&pg=PR9\&dq=buena + aplicaci $\% \mathrm{C} 3 \% \mathrm{~B} 3 \mathrm{n}+\mathrm{de}+\mathrm{l}$ as $+\mathrm{pol} \% \mathrm{C} 3 \%$ ADticas $+\mathrm{p} \% \mathrm{C} 3 \% \mathrm{BAblicas},+$ se + requiere + un + riguroso + seguimiento + que + eval $\% \mathrm{C} 3 \% \mathrm{BAe}+$ su + eficiencia + mientra $\mathrm{s}+\&$ ots $=$ Meh7V_ZE-3\&sig=aQbymz9qujqViiE0rV62_N6ALFI\&redir_esc $=\mathrm{y} \#_{\mathrm{v}}=$ onepage $\& \mathrm{q} \& \mathrm{f}=$ false.

8 FRANCISKOVIC, Jubitza. Retos de la gestión pública: presupuesto por resultados y rendición de cuentas. Journal of Economics, Financeand Administrative Science, v. 18, p. 28-32, 2013. Disponible en: https://www.sciencedirect.com/science/article/pii/ S2077188613700283.

9 BUENO SUÁREZ, Carlos; OSUNA LLANEZA, José Luis. Reflexiones epistemológicas y metodológicas para la evaluación de políticas públicas. Andamios: Revista de Investigación Social, v. 10, n. 21, p. 95-117, ene./abr. 2013. Disponible en: https://www. redalyc.org/pdf/628/62828836005.pdf.

${ }^{10}$ BLANCO, Ismael; GOMÀ, Ricard. La crisis del modelode gobierno tradicional: reflexiones en torno a la governance participativa y de proximidad. Gestión y Política Pública, v. 12, n. 1, p. 5-42, 2003. Disponible en: https://www.redalyc.org/pdf/133/13312101.pdf.

11 CASTELAO CARUANA, María Eugenia. Las políticas públicas y su visión de la economía social y solidaria en Argentina. Revista Mexicana de Ciencias Politicas y Sociales, v. 61, n. 227, 2016. Disponible en: http://www.revistas.unam.mx/index.php/rmcpys/article/view/49598.

12 CAMPBELL, Siobhan; BENITA, Siobhan; COATES, Elizabeth; DAVIES, Phil; PENN, Gemma. Analysis for policy: evidencebased policy in practice. London: HM Treasury, 2007. Disponible en: https://www.srhr-ask-us.org/publication/analysis-policyevidence-based-policy-practice/.

13 FLORES, Pedro. El enfoque de la política basado en la evidencia: análisis de su utilidad para la educación de México. Revista mexicana de investigación educativa, v. 18, n. 56, p. 265-290, 2013. Disponible en: http://www.scielo.org.mx/scielo.php?pid=S140566662013000100012\&script $=$ sci_arttext.

14 BERTRANOU, Julián. El seguimiento y la evaluación de políticas públicas. Modelos disponibles para producir conocimiento y mejorar el desempeño de las intervenciones públicas. Millcayac Revista Digital de Ciencias Sociales, v. 6, n. 10, p. 151-188, 2019. Disponible en: https://revistas.uncu.edu.ar/ojs3/index.php/millca-digital/article/view/1730.
} 
El gráfico 1, demuestra la forma interrelacionada como podrían estar los actores del cuerpo directivo del ámbito público y representantes de las comunidades afectadas, quienes sugieren desde sus respectivos campos de acción soluciones que surgen desde los objetivos planteados en armonía de estrategias implementadas mediante la dicotomía administrativa de la política pública y sus niveles de realimentación en función de su efectividad.

\subsubsection{Explicación de la Ley 1448 de 2.011}

La historia colombiana, se ha caracterizado por vivir un conflicto armado interno y al que el gobierno de turno, ha buscado darle fin a dicho fenómeno. Sin embargo, la presencia de diferentes grupos armados al margen de la ley y la debilidad institucional, ha dificultado el cese de la violencia en el país ${ }^{15}$. La ley 975 de Justicia y Paz en el $2005^{16}$, es una muestra de los intentos que, en materia de reparación, Colombia viene realizando. Para el año 2010 y con el inicio de gobierno de Juan Manuel Santos, se continúa con la ofensiva militar contra los grupos guerrilleros, pero además se les da el reconocimiento a las víctimas mediante la adopción e implementación de la Ley 1448 o Ley de Víctimas y de Restitución de Tierras en julio de 2011 y también se inicia el proceso de paz con las Farc en el año $2012^{17},{ }^{18}$.

Esta ley tiene por objeto establecer un conjunto de medidas judiciales, administrativas, sociales y económicas, individuales y colectivas en beneficio de las víctimas de las violaciones contempladas en el artículo 3 donde

consideran víctimas para los efectos de esta ley, aquellas personas que individual o colectivamente hayan sufrido un daño por hechos ocurridos a partir del 1 de enero de 1.985, como consecuencia de infracciones al Derecho Internacional Humanitario o de violaciones graves y manifiestas a las normas Internacionales de Derechos Humanitarios, ocurridos con ocasión del conflicto armado interno ${ }^{19}$.

La Unidad para las Víctimas es la coordinadora de las entidades que hacen parte del Sistema Nacional de Atención y Reparación Integral a las Víctimas - SNARIV, identificando toda la oferta institucional disponible y dirigida a la población incluida en el Registro Único de Víctimas ${ }^{20}$. Se brinda una atención con enfoque diferencial implementando programas, proyectos y acciones que den cumplimiento a la Ley 1448 del 2011. Se encuentra conformado por entidades públicas de orden nacional y territorial y demás organizaciones públicas o privadas, que contribuyan de acuerdo a su competencia en el proceso de reparación integral de las víctimas. Dentro del SNARIV se encuentran instituciones como: Archivo General de la Nación, Agencia de la Reincorporación Bancóldex, Banco Agrario de Colombia, Centro de Memoria Histórica, Contraloría, Programa Presidencial de Derechos Humanos y DIH, Defensoría del Pueblo, Departamento Nacional de Planeación, Prosperidad Social, Fiscalía General de la Nación, Ministerio de Agricultura, Finagro, Instituto

\footnotetext{
15 NIÑO, César. Breve historia del conflicto armado en Colombia. Revista de pary conflictos, v. 10, n. 1, p. 327-330, 2017. Disponible en: https://www.redalyc.org/pdf/2050/205052042015.pdf.

16 CONGRESO DE COLOMBIA. Ley 975 de 2005: por la cual se dictan disposiciones para la reincorporación de miembros de grupos armados organizados al margen de la ley, que contribuyan de manera efectiva a la consecución de la paz nacional y se dictan otras disposiciones para acuerdos humanitarios. 25 de julio de 2005. Disponible en: https://www.unidadvictimas.gov.co/es/ley975-del-25-de-julio-de-2005/14849.

17 CENTRO DE MEMORIA HISTÓRICA. Los orígenes, las dinámicas y el crecimiento del conflicto armado. In: ;Basta ya! Colombia: Memorias de Guerra y Dignidad: informe general grupo de memoria histórica. 2016. p. 111-194. Disponible en: http:// centrodememoriahistorica.gov.co/descargas/informes2013/bastaYa/capitulos/basta-ya-cap2_110-195.pdf.

18 RODRIGUEZ TOVAR, Sergio Enrique. Transferencia y acceso a la tierra en contextos de violencia: análisis empírico para el municipio de Guadalajara de Buga, 2001-2013. 2016. Disertación (Maestría en Economía Aplicada) - Facultad de Ciencias Sociales y Económicas, Universidad del Valle, Cali, 2016. Disponible en: http://bibliotecadigital.univalle.edu.co/bitstream/10893/9897/1/0534285ME-2016-2.pdf.

19 GONZÁLEZ, Julio. Verdad, justicia, paz y reparación en la mitología penal: a propósito de la ley 975 de 2005 . Estudios politicos, Medellín, n. 27, p. 45-63, 2005. Disponible en: https://bibliotecadigital.udea.edu.co/handle/10495/8718.

${ }^{20}$ UNIDAD PARA LAS VÍCTIMAS. Fondo para la reparación s las víctimas. S.f. Disponible en: http://www.unidadvictimas.gov.co/ es/fondo-para-la-reparaci $\% \mathrm{C} 3 \% \mathrm{~B} 3 \mathrm{n}-\mathrm{las}-\mathrm{v} \% \mathrm{C} 3 \% \mathrm{AD}$ ctimas $/ 80$.
} 
Colombiano de Bienestar Familiar, Icetex, Ministerio de Cultura, Ministerio de Educación, Ministerio de Hacienda, Ministerio de Justicia, Ministerio de Salud, Ministerio de Tics, Ministerio de Vivienda, Ministerio de Relacione Exteriores, Ministerio de Trabajo, Policía Nacional, Procuraduría General de la Nación, Registraduría Nacional del Estado Civil, Servicio Nacional de Aprendizaje, Unidad de Restitución de Tierras, entre otras ${ }^{21}$.

Teniendo en cuenta que dicha ley se determinó con una vigencia de diez años, el gobierno nacional debía garantizar su financiación y mediante el Conpes 3712 del mismo año ${ }^{22}$, determina el Plan de Financiación para la sostenibilidad de la Ley 1448 y así dar cumplimiento al principio de sostenibilidad llevando a cabo medidas de ayuda humanitaria, atención, asistencia y reparación.

En el artículo 25 de la misma ley, se plantea que la reparación comprende medidas de restitución, indemnización, rehabilitación, satisfacción y garantías de no repetición, en sus dimensiones individual, colectiva, material, moral y simbólica. Dentro de los componentes se encuentran aspectos como la salud, educación, vivienda, asistencia funeraria, generación de ingresos, entre otros, que de manera individual o colectiva conduzcan al restablecimiento socioeconómico de la población víctima del conflicto $\operatorname{armado}^{23}{ }^{24}$.

Esta necesidad sentida ya se venía estableciendo en el país con leyes como la 387 de 1997 donde se plantea crear medios de subsistencia por parte de la población desplazada para su re estabilización socioeconómica, el Decreto 173 de 1998 donde se identifican fuentes de financiación, pero no hubo una adecuada articulación interinstitucional ${ }^{25}$. En el año 2004, con la Sentencia T 025 la Corte Constitucional declaró la existencia de un Estado de Cosas Inconstitucional por el incumplimiento por parte del Estado de ser garante de los derechos fundamentales para la población víctima como consecuencia del conflicto armado. Posterior a la Ley 1448 de 2011, a finales del mismo año, el Ministerio del Interior genera el Decreto 4800 para definir los mecanismos adecuados en la implementación de las medidas de asistencia, atención y reparación integral a las víctimas definidas en el artículo $3^{\circ}$ de la Ley 1448 de $2011^{26}$.

En el artículo 130 de la ley 1448 de 2011, se establece que el Sena y el Ministerio de Protección Social (hoy Ministerio de Trabajo) “diseñará programas y proyectos especiales para la generación de empleo rural y urbano con el fin de apoyar el autosostenimiento de las víctimas, el cual se implementará a través del Plan Nacional para la Atención y Reparación Integral a las Víctimas" ${ }^{27}$.

Dando cumplimiento, el Estado colombiano ha realizado programas de empleabilidad a nivel rural y urbano en lo relacionado con la vinculación laboral y el emprendimiento, tal y como se puede observar en la Tabla 1, que se presenta a continuación.

\footnotetext{
${ }^{21}$ SNARIV. Entidades que conforman el sistema nacional de atención y reparación integral a las víctimas. S.f. Disponible en: http://www.portalsnariv.gov.co/node/1000\#: :text=Departamento $\% 20$ Nacional $\% 20 \mathrm{de} \% 20 \mathrm{Planeaci} \% \mathrm{C} 3 \% \mathrm{~B} 3 \mathrm{n} \% 20 \% 2 \mathrm{DDNP}$,fng.gov.co $\% 2 \mathrm{FES}$.

22 COLOMBIA. Mininterior. Conpes 3712 de 2011: plan de financiación para la sostenibilidad de la Ley 1448 de 2011.1 de diciembre 2011. Disponible en: https://www.mininterior.gov.co/content/conpes-3712-de-2011.

23 ARÉVALO, Estefania; SOTOMAYOR, Carolina. La restitución de tierras consagrada en la Ley 1448 de 2011, a la luz de la teoría neoconstitucionalista. Revista Academía y Derecho, v. 7, n. 13, p. 91-118, 2016. Disponible en: http://190.143.117.169/ojs/index.php/ derecho/article/view/124.

24 SERRANO GÓMEZ, Rocío; ACEVEDO PRADA, Milena. Reflexiones en torno a la aplicación de la Ley 1448 de 2011 y la restitución de tierras en Colombia. Revista de la facultad de derecho y ciencias políticas, Medellín, v. 43, n. 118, p. 533-566, ene./jun. 2013. Disponible en: http://www.scielo.org.co/pdf/rfdcp/v43n119/v43n119a03.pdf.

25 ZARAMA VÁZQUES, Ernesto. Generación de ingresos para la población desplazada en Colombia: perspectivas desde abajo. Santiago de Chile, 2009. Disponible en: https://repositorio.cepal.org/bitstream/handle/11362/6158/1/S0900694_es.pdf.

${ }_{26}$ COLOMBIA. Minjusticia. Decreto 4800 de 2011: por el cual se reglamenta la Ley 1448 de 2011 y se dictan otras disposiciones. 20 de diciembre 2011. Disponible en: https://www.unidadvictimas.gov.co/es/decreto-4800-de-2011/13108.

27 CONGRESO DE COLOMBIA. Ley 448 de 2011: Artículo 51 y 130, de 10 de junio, por la cual se dictan medidas de atención, asistencia y reparación integral a las víctimas del conflicto armado interno y se dictan otras disposiciones. 10 de junio de 2011. Disponible en: https://www.unidadvictimas.gov.co/es/ley-1448-de-2011/13653.
} 
Tabla 1 - Programas de empleabilidad rural y urbano

\begin{tabular}{|c|c|c|c|c|}
\hline PROGRAMA & ALIADOS & VIGENCIA & $\begin{array}{l}\text { POBLACIÓN } \\
\text { OBJETO }\end{array}$ & $\begin{array}{l}\text { FUENTE DE } \\
\text { INGRESOS }\end{array}$ \\
\hline $\begin{array}{l}\text { Educándonos para } \\
\text { la paz }{ }^{28}\end{array}$ & $\begin{array}{l}\text { Liderado por el } \\
\text { Ministerio del Tra- } \\
\text { bajo con la coope- } \\
\text { ración y asistencia } \\
\text { técnica de la Orga- } \\
\text { nización Interna- } \\
\text { cional del Trabajo } \\
\text { (OIT) y la Organi- } \\
\text { zación de Estados } \\
\text { Iberoamericanos } \\
\text { para la Educación, } \\
\text { la Ciencia y a la } \\
\text { Cultura (OEI). }\end{array}$ & $\begin{array}{l}12 \text { de diciembre de } \\
2016 \text { - } 31 \text { de di- } \\
\text { ciembre de } 2018 .\end{array}$ & $\begin{array}{l}\text { 3.025 víctimas } \\
\text { en } 16 \text { ciudades: } \\
\text { Armenia, Barran- } \\
\text { cabermeja, Bar- } \\
\text { ranquilla, Bogotá, } \\
\text { Bucaramanga, Cali, } \\
\text { Cartagena, Cúcuta, } \\
\text { Manizales, Me- } \\
\text { dellín, Montería, } \\
\text { Pasto, Pereira, Po- } \\
\text { payán, Villavicen- } \\
\text { cio y Santa Marta } \\
\text { en programas de } \\
\text { formación en Sof- } \\
\text { tware Cocina, } \\
\text { Diseño Gráfico } \\
\text { Digital, Adminis- } \\
\text { tración, Contabi- } \\
\text { lidad y Finanzas, } \\
\text { Mercadeo y Ven- } \\
\text { tas, Salud, Call y } \\
\text { Contact Center } \\
\text { y Hotelería y Tu- } \\
\text { rismo. A la fecha } \\
\text { 3.074 estudiantes } \\
\text { han terminado su } \\
\text { proceso lectivo y } \\
\text { adelantan la prácti- } \\
\text { ca laboral. }\end{array}$ & $\begin{array}{l}\text { Fortalecimiento } \\
\text { vocacional para la } \\
\text { inserción laboral. }\end{array}$ \\
\hline
\end{tabular}

${ }^{28}$ COLOMBIA. Mintrabajo. Educándonos para la pa\%: 2016. Disponible en: https://www.mintrabajo.gov.co/el-ministerio/reparacion-integral-victimas/formacion-para-el-trabajo-y-vocacional/educandonos-para-la-paz. 


\begin{tabular}{|c|c|c|c|c|}
\hline PROGRAMA & ALIADOS & VIGENCIA & $\begin{array}{l}\text { POBLACIÓN } \\
\text { OBJETO }\end{array}$ & $\begin{array}{l}\text { FUENTE DE } \\
\text { INGRESOS }\end{array}$ \\
\hline TransFórmate ${ }^{29}$ & $\begin{array}{l}\text { Instituto Colom- } \\
\text { biano de Crédito } \\
\text { Educativo y Estu- } \\
\text { dios Técnicos en } \\
\text { el Exterior - ICE- } \\
\text { TEX }\end{array}$ & $\begin{array}{l}\text { Diciembre de } 2013 \\
\text { - Diciembre } 2017\end{array}$ & $\begin{array}{l}4625 \text { jóvenes par- } \\
\text { ticipantes entre } \\
16 \text { y } 28 \text { años que } \\
\text { se encuentran en } \\
\text { etapa de repara- } \\
\text { ción de Apartadó, } \\
\text { Envigado, Me- } \\
\text { dellín, Rionegro, } \\
\text { Barranquilla, Sole- } \\
\text { dad, Bogotá, D.C., } \\
\text { Montería, Neiva, } \\
\text { Santa Marta, Villa- } \\
\text { vicencio, Cúcuta, } \\
\text { Barrancabermeja, } \\
\text { Bucaramanga, } \\
\text { Sincelejo, Buena- } \\
\text { ventura, Cali, Gua- } \\
\text { dalajara de Buga, } \\
\text { Palmira, Tuluá. }\end{array}$ & $\begin{array}{l}\text { Orientación voca- } \\
\text { cional para la in- } \\
\text { serción laboral. }\end{array}$ \\
\hline $\begin{array}{l}\text { Orientados hacia } \\
\text { la } \mathrm{Paz}^{30}\end{array}$ & $\begin{array}{l}\text { Organización Ibe- } \\
\text { roamericana de } \\
\text { Seguridad Social } \\
\text { OISS. }\end{array}$ & 2018 & $\begin{array}{l}\text { Orientación voca- } \\
\text { cional dirigido a } \\
600 \text { jóvenes entre } \\
16 \text { y } 21 \text { años vícti- } \\
\text { mas del conflicto } \\
\text { armado que se en- } \\
\text { cuentran en etapa } \\
\text { de reparación. }\end{array}$ & $\begin{array}{l}\text { Orientación voca- } \\
\text { cional para la in- } \\
\text { serción laboral. }\end{array}$ \\
\hline
\end{tabular}

${ }_{29}$ COLOMBIA. Mintrabajo. TransFórmate. 2013. Disponible en: https://www.mintrabajo.gov.co/el-ministerio/reparacion-integralvictimas/formacion-para-el-trabajo-y-vocacional/transformate.

${ }^{30}$ COLOMBIA. Mintrabajo. Orientados hacia la pa: 2018. Disponible en: https://www.mintrabajo.gov.co/el-ministerio/reparacionintegral-victimas/formacion-para-el-trabajo-y-vocacional/orientados-hacia-la-paz. 


\begin{tabular}{|c|c|c|c|c|}
\hline PROGRAMA & ALIADOS & VIGENCIA & $\begin{array}{l}\text { POBLACIÓN } \\
\text { OBJETO }\end{array}$ & $\begin{array}{l}\text { FUENTE DE } \\
\text { INGRESOS }\end{array}$ \\
\hline $\begin{array}{l}\text { Somos rurales y } \\
\text { Emprendiendo } \\
\text { sueños (antes Su- } \\
\text { mando Paz) }{ }^{31}\end{array}$ & $\begin{array}{l}\text { Programa de las } \\
\text { Naciones Unidas } \\
\text { para el Desarrollo- } \\
\text {-PNUD }\end{array}$ & 2014-2020 & $\begin{array}{l}\text { Familias en An- } \\
\text { tioquia, Arauca, } \\
\text { Bolívar, Cauca, } \\
\text { Cesar, Casanare, } \\
\text { Cundinamarca, } \\
\text { Córdoba, Caquetá, } \\
\text { Magdalena, Na- } \\
\text { riño, Norte de San- } \\
\text { tander, Putumayo, } \\
\text { Quindío, Risaralda, } \\
\text { Sucre, Santander, } \\
\text { Tolima y Valle del } \\
\text { Cauca. }\end{array}$ & $\begin{array}{l}\text { Somos Rura- } \\
\text { les promueve la } \\
\text { implementación de } \\
\text { emprendimientos } \\
\text { que garanticen la } \\
\text { inserción económi- } \\
\text { ca de las familias } \\
\text { rurales. Por cuenta } \\
\text { de su enfoque di- } \\
\text { ferencial, busca la } \\
\text { inclusión producti- } \\
\text { va de las personas } \\
\text { con discapacidad } \\
\text { que habitan en } \\
\text { zonas rurales. } \\
\text { Emprendiendo } \\
\text { Sueños apoya la } \\
\text { implementación } \\
\text { de medidas de re- } \\
\text { paración colectiva. } \\
\text { Sectores econó- } \\
\text { micos distintos a } \\
\text { los agropecuarios } \\
\text { a través del forta- } \\
\text { lecimiento técnico, } \\
\text { empresarial, orga- } \\
\text { nizacional, social y } \\
\text { comercial. }\end{array}$ \\
\hline
\end{tabular}

31 PROGRAMA DE LAS NACIONES UNIDAS PARA EL DESARROLLO. Emprendimiento y empleabilidad para familias rurales victimas del conflicto armado: Desarrollo Incluyente Rural para familias víctimas del conflicto. 2020. Disponible en: https://www.co.undp. org/content/colombia/es/home/projects/emprendimiento-y-empleabilidad-para-familias-rurales-victimas-de.html. 


\begin{tabular}{|c|c|c|c|c|}
\hline PROGRAMA & ALIADOS & VIGENCIA & $\begin{array}{l}\text { POBLACIÓN } \\
\text { OBJETO }\end{array}$ & $\begin{array}{l}\text { FUENTE DE } \\
\text { INGRESOS }\end{array}$ \\
\hline $\begin{array}{l}\text { Emprendiendo } \\
\text { Retornos }^{32}\end{array}$ & $\begin{array}{l}\text { Corporación } \\
\text { Nuevo Arco Iris - } \\
\text { CNAI }\end{array}$ & $\begin{array}{l}\text { Mayo } 2017 \text { a Di- } \\
\text { ciembre } 2017 .\end{array}$ & $\begin{array}{l}63 \text { unidades pro- } \\
\text { ductivas de fami- } \\
\text { lias priorizadas que } \\
\text { se encontraban en } \\
\text { proceso de reubi- } \\
\text { cación o retorno. } \\
\text { Estas unidades } \\
\text { productivas son de } \\
\text { Bogotá, Florencia } \\
\text { (Caquetá), Puerto } \\
\text { Inírida (Guainía), } \\
\text { Pasto (Nariño), } \\
\text { Colón (Putumayo), } \\
\text { Rionegro (An- } \\
\text { tioquia), Ibagué } \\
\text { (Tolima) y Puerto } \\
\text { Carreño (Vichada). }\end{array}$ & $\begin{array}{l}\text { Emprendimientos } \\
\text { que ha potenciado } \\
\text { la participación } \\
\text { de víctimas como } \\
\text { gestores y provee- } \\
\text { dores de servicio. }\end{array}$ \\
\hline $\begin{array}{l}\text { Colombia Em- } \\
\text { prende }^{33}\end{array}$ & $\begin{array}{l}\text { Organización de } \\
\text { Estados Iberoa- } \\
\text { mericanos para } \\
\text { la Educación, la } \\
\text { Ciencia y a la Cul- } \\
\text { tura (OEI). }\end{array}$ & 2018 & $\begin{array}{l}\text { En los departa- } \\
\text { mentos de An- } \\
\text { tioquia, Caldas, } \\
\text { Cauca, Córdoba, } \\
\text { Cundinamarca, } \\
\text { Meta, Nariño, } \\
\text { Norte de Santan- } \\
\text { der, Putumayo, } \\
\text { Quindío, Risaralda, } \\
\text { Santander, Tolima } \\
\text { y Valle del Cauca. }\end{array}$ & $\begin{array}{l}\text { Unidades pro- } \\
\text { ductivas para su } \\
\text { fortalecimiento } \\
\text { productivo }\end{array}$ \\
\hline
\end{tabular}

32 COLOMBIA. Mintrabajo. Emprendiendo retornos. 2017. Disponible en: https://www.mintrabajo.gov.co/el-ministerio/reparacionintegral-victimas/emprendimiento/emprendiendo-retornos.

33 OEI. Programa Colombia Emprende. 2020. Disponible en: https://oei.int/oficinas/colombia/noticias/pre-inscripcion-fase-i-delprograma-colombia-emprende. 


\begin{tabular}{|c|c|c|c|c|}
\hline PROGRAMA & ALIADOS & VIGENCIA & $\begin{array}{l}\text { POBLACIÓN } \\
\text { OBJETO }\end{array}$ & $\begin{array}{l}\text { FUENTE DE } \\
\text { INGRESOS }\end{array}$ \\
\hline $\begin{array}{l}\text { El futuro es de los } \\
\text { jóvenes }^{34}\end{array}$ & $\begin{array}{l}\text { Organización } \\
\text { Internacional del } \\
\text { Trabajo-OIT y la } \\
\text { Organización de } \\
\text { Estados Iberoa- } \\
\text { mericanos para } \\
\text { la Educación, la } \\
\text { Ciencia y la Cultu- } \\
\text { ra -OEI }\end{array}$ & $\begin{array}{l}26 \text { julio - } 31 \text { di- } \\
\text { ciembre } 2019\end{array}$ & $\begin{array}{l}\text { Fortalecimiento de } \\
\text { habilidades blan- } \\
\text { das, transversales } \\
\text { y de orientación } \\
\text { vocacional frente } \\
\text { a los proyectos } \\
\text { de vida, dirigida a } \\
650 \text { jóvenes que se } \\
\text { encuentran en pro- } \\
\text { ceso de indemniza- } \\
\text { ción de los munici- } \\
\text { pios de Aguachica, } \\
\text { Agustín Codazzi, } \\
\text { Barrancabermeja, } \\
\text { Carmen de Bolívar, } \\
\text { Ciénaga, Cúcuta, } \\
\text { Dos Quebradas, } \\
\text { Fundación, Floren- } \\
\text { cia, Neiva, Pitalito, } \\
\text { Pereira, Popayán, } \\
\text { San Diego, Santa } \\
\text { Marta, Soledad, } \\
\text { Villavicencio y } \\
\text { Yopal. }\end{array}$ & $\begin{array}{l}\text { Orientación voca- } \\
\text { cional y fortaleci- } \\
\text { miento de habili- } \\
\text { dades blandas que } \\
\text { faciliten la inser- } \\
\text { ción en el mercado } \\
\text { laboral. }\end{array}$ \\
\hline
\end{tabular}

Fuente: elaboración propia a partir de información de Ministerio del Trabajo y aliados.

Con respecto al tema de generación de ingresos y teniendo en cuenta los componentes de reparación, el objeto de estudio se centra en generación de ingresos y tomando el emprendimiento como uno de los ejes claves en este aspecto.

\subsubsection{Emprendimiento}

\subsubsection{Conceptos}

El emprendedor juega un papel importante al tener la capacidad de generar ideas y plantear alternativas con base a las oportunidades presentes en el entorno, contribuyendo así al desarrollo empresarial tanto con la creación de organizaciones como también aportando a la configuración socioeconómica de las regiones al acceso a recursos a los más pobres para que constituyan sus propias empresas ${ }^{35}$, ${ }^{36}$. La relación entre la autoeficacia empresarial y la intención empresarial está mediada por la actitud hacia el emprendimiento y

\footnotetext{
34 OIT. Proyecto el futuro de los jóvenes. 2019. Disponible en: https://www.ilo.org/lima/programas-y-proyectos/WCMS_731346/lang-es/index.htm.

35 BRAVO GARCÍA, Saulo. Análisis de las características de un emprendedor en proceso de incubación y no incubados. Sotavento M.B.A., v. 21, p. 40-48, ene./jun. 2013. Disponible en: https://revistas.uexternado.edu.co/index.php/sotavento/article/ view/3435/3122.

36 DUARTE, Tito; RUIZ, Myriam. Emprendimiento, una opción para el desarrollo. Scientia Et Technica, v. 15, n. 43, p. 326-331, 2009. Disponible: https://www.redalyc.org/pdf/849/84917310058.pdf.
} 
control conductual percibido ${ }^{37}$, la relación existente entre progreso y crecimiento económicos y el papel relevante que desempeñan los emprendedores ${ }^{38}$. De igual forma, existen factores que intervienen en el emprendimiento entre los más importantes están: factores endógenos y exógenos ${ }^{39}$. Además, es importante destacar que, los emprendimientos productivos apuntalan desde su origen la inclusión social, al dar lugar a bienes o servicios con el objeto de que los procesos de producción y la inserción en el mercado, propicien el desarrollo personal y la integración social de las personas que se hallan excluidos ${ }^{40}$.

\subsubsection{Tipos de emprendimiento}

Existen diversidad de clasificación de los emprendimientos dentro de la literatura teniendo en cuenta diferentes aspectos al momento de categorizarlos y la dinámica en donde se desarrollen.

El tipo de emprendimiento tiene una relación directa con la motivación a emprender y resultado de esto se diferencia el emprendimiento por oportunidad y el emprendimiento por necesidad ${ }^{41}$. En el primer caso es aquella que se da para aprovechar una oportunidad de negocio identificada y en el segundo sucede cuando no se logra fácilmente vincularse laboralmente a una empresa o no satisface las expectativas $\stackrel{42,43,44.45}{42}$

De acuerdo al tipo de economía en el que se desarrollan los emprendimientos, influyen en la clase en que estos se generan. En las economías débiles o en los países que se encuentran en vía de desarrollo, predominan los emprendimientos por necesidad ${ }^{46},{ }^{47}$ y en las economías más fuertes, se propician los emprendimientos por oportunidad ${ }^{48}$.

\footnotetext{
37 DOANHA, Duong Cong; TRANG, Tran Van. Entrepreneurial self-efficacy and intention among vietnamese students: a metaanalytic path analysis based on the theory of planned behavior. Management Science Letters, v. 9, p. 1847-1862, 2019. Disponible en: https://www.growingscience.com/msl/Vol9/msl_2019_154.pdf.

38 GALINDO-MARTÍNA, Miguel Ángel; MÉNDEZ-PICAZO, María Teresa; CASTAÑO-MARTÍNEZ, María Soledad. Crecimiento, progreso económico y emprendimiento. Journal of Innovation \& Knowledge, v. 1, p. 62-68, 2016. Disponible en: https://www. econstor.eu/bitstream/10419/190693/1/1023020734.pdf.

39 JIMÉNEZ-SILVA, Walter; LARREA-ALTAMIRANO, Janeth; NAVARRETE-FONSECA, Mario; CASTRO-AYALA, Edisson. Emprendimientos innovadores a partir de competencias cognitivas en estudiantes universitarios. Revista venezolana de gerencia, v. $24, \mathrm{n}$. 85, 2019. Disponible en: https://www.redalyc.org/articulo.oa?id=29058864004.

40 OCA ROJAS, Y. M. M. Perspectivas del emprendimiento social y redes socioproductivas de pequeños productores en Venezuela. Revista de ciencias sociales, v. 26, n. 1, p. 300-312, ene./mar. 2020. Disponible en: https://produccioncientificaluz.org/index.php/rcs/ article/view/31326/32376.

41 GEM. Global Entrepreneurship Monitor 2014: Global Report. Disponible en: https://www.gemconsortium.org/report/gem2014-global-report.

42 REYNOLDS, Paul D.; BYGRAVE, William D.; AUTIO, Erkko; COX, Larry W.; HAY, Michael. Global entrepreneurship Monitor: 2002 executive report. Kansas City: Kauffman Center for Entrepreneurial Leadership, 2002. Disponible en: http://www.esbri.se/ gemglobalreport_2002.pdf.

43 BENZ, Matthias. Entrepreneurship as a non-profit seeking activity. International Entrepreneurship and Management Journal, v. 5, p. 23-44, 2009. Disponible en: https:/ link.springer.com/article/10.1007/s11365-006-0031-y.

44 DEVINS, D. Enterprise in deprived areas: what role for start-ups?. International Journal of Entrepreneurship and Small Business, v. 8, p. 486-498, 2009. Disponible en: https://www.researchgate.net/publication/260338809_Is_Informal_Sector_Entrepreneurship_Necessity-_or_Opportunity-driven_Some_Lessons_from_Urban_Brazil.

45 GIACOMIN, Olivier; JANSSEN, Frank; GUYOT, Jean-Luc; LOHEST, Olivier. Opportunity and/ or necessity entrepreneurship?: the impact of the socio-economic characteristics of entrepreneurs. Munich: MPRA, 2011. Disponible en: https://mpra.ub.unimuenchen.de/29506/2/MPRA_paper_29506.pdf.

46 CANCINO, Christian; BONILLA, Claudia. Financiamiento público al emprendimiento chileno: un análisis chileno. Trend Management, p. 156-161, 2011.

47 LARROULET, Cristián; RAMÍREZ, Macarena. Emprendimiento: factor clave para la nueva etapa de Chile. In: DURÁN, P. (ed.). Emprendimiento e innovación en Chile. Santiago: Facultad de Economía y Negocios, Universidad del Desarrollo, 2008. p. 15-38. Disponible en: https://www.academia.edu/14148885/Emprendimiento_e_Innovaci\%C3\%B3n_en_Chile_Una_Tarea_Pendiente.

48 AMORÓS, José Ernesto; FERNÁNDEZ, Crsitóbal; TAPIA, Juan. Quantifying the relationship between entrepreneurship and competitiveness development stages in Latin America. International Entrepreneurship and Management Journal, v. 8, p. 249-270, 2012. Disponible en: https://link.springer.com/article/10.1007/s11365-010-0165-9.
} 


\subsubsection{Tendencias de supervivencia de emprendimiento}

A pesar de que Colombia es una nación emprendedora, un estudio de Confecámaras en el 2016 afirma que la supervivencia de las empresas es del 78.3\% en su primer año de creación, 61\% de sobrevivencia en el tercer año y del $42.9 \%$ en el quinto año y sólo el $40 \%$ de las empresas siguen funcionando a partir de los cinco años de su creación ${ }^{49}$.

En la creación de empresas, lidera el sector de consumo que se caracteriza por bajos niveles de innovación, poca transmisión del conocimiento y similitud en los productos, además de poca generación de empleos, mientras que el sector de la transformación y servicios impulsa a la creación de nuevos empleos.

\section{Metodología}

La metodología de esta investigación se concentró en tres etapas. La primera de ellas se relaciona con la definición del tema de investigación incorporado dentro de los pasos lógicos y partes claves que conforman el anteproyecto. Posteriormente, se definió la ruta que condujera a los resultados del análisis de este estudio. En este sentido, se buscó el soporte teórico y se definieron los pasos y los instrumentos para la toma de la información y su posterior análisis. Por lo tanto, se llevó a cabo el siguiente proceso:

- Identificación de fuentes secundarias idóneas en información de literatura científica desde las bases de datos de Science Direct, Scopus, Google Scholar e Informe Académico que permitieron mediante el meta-análisis, identificar el objeto y sujeto de estudio.

- Ubicación geográfica de población con características tenidas en cuenta para el estudio como fuentes primarias.

- Aplicación del instrumento denominado estudio del arte de las unidades productivas de los años 2017 al 2019, diseñado por el programa de Atención a Población Víctima del Conflicto Armado del Sena.

- Análisis e interpretación de resultados a través de la Matriz del estado del arte de las unidades productivas.

Como una segunda etapa, se realizó un análisis de las características que componen la ley 1448 de 2011 relacionada con la implementación en los procesos de reparación a las víctimas del conflicto armado interno en cuanto al componente de generación de ingresos. Este estudio se presenta como un análisis de caso en el Valle del Cauca.

\subsection{Hipótesis}

\subsubsection{Hipótesis 1}

La falta de articulación interinstitucional dificulta que los emprendedoras, víctimas del conflicto armado, tengan una fuente de generación de ingresos sostenible en el tiempo.

\footnotetext{
49 CONFECAMARAS. Nacimiento y Supervivencia de las empresas en Colombia. 2016. Disponible en: https://www.confecamaras.org.co/ phocadownload/Cuadernos_de_analisis_economico/Cuaderno_de_An\%D0\%B0lisis_Economico_N_11.pdf.
} 


\subsubsection{Hipótesis 2}

La población víctima del conflicto armado que decide emprender al igual que otro tipo de población, en el momento de desarrollar su actividad, no logra un equilibrio económico.

\section{Resultados y discusión}

\subsection{Estructura de herramienta utilizada}

El Sena como una de las entidades competentes y pertenecientes al SNARIV en el 2020, aplicó una herramienta de diagnóstico para conocer el estado de 57 unidades productivas atendidas en el Valle del Cauca durante los años 2017 a 2019. Esta herramienta contiene la siguiente estructura ${ }^{50}$.

Figura 1 - Herramienta de Diagnóstico Empresarial

\begin{tabular}{|l|}
\multicolumn{1}{|c|}{ HERRAMIENTA DE DIAGNOSTICO EMPRESARIAL DE UNIDADES PRODUCTIVAS } \\
\hline FECHA DE APLICACIÓN DE ENCUESTA \\
\hline REGIONAL \\
\hline CENTRO DE FORMACION \\
\hline NOMBRE DEL EMPRENDEDOR \\
\hline NRO DOCUMENTO \\
\hline TELÉFONO DE CONTACTO \\
\hline DIRECCIÓN DEL EMPRENDEDOR \\
\hline CORREO ELECTRONICO \\
\hline GRUPO ÉTNICO \\
\hline NOMBRE DE LA UNIDAD PRODUCTIVA \\
\hline DIRECCIÓN DE LA UNIDAD PRODUCTIVA \\
\hline ACTIVIDAD ECONÓMICA \\
\hline SECTOR \\
\hline PRODUCTO/SERVICIO \\
\hline SUBPRODUCTOS \\
\hline PROFESIONAL RESPONSABLE DE LA APLICACIÓN DE LA ENCUESTA \\
\hline DATOS DE CONTACTO ALTERNO \\
\hline
\end{tabular}

Fuente: el Sena (2020)

En este fragmento se compila las características demográficas de los emprendedores y sus unidades productivas.

Por otro lado, se realiza un análisis de los indicadores, donde se consideran aspectos de operación con un peso del 15\%, factores administrativos con un peso del 15\%, mercado con un peso del $20 \%$, contable y financiero con un peso del 20\% y fuentes de financiación con un peso del $30 \%$. Para todos los indicadores se maneja una escala de No cumple $=0$, Cumple parcialmente $=1$, Cumple totalmente $=2$ que se resumen en la siguiente tabla:

Tabla 2 - Indicadores y peso porcentual

\begin{tabular}{ll}
\hline INDICADORES & PESO PORCENTUAL \\
\hline Aspectos de Operación & 15 \\
\hline Aspectos Administrativos & 15 \\
\hline Aspectos de Mercado & 20 \\
\hline Aspectos Contable y Financiero & 20 \\
\hline Fuentes de Financiación & 30 \\
\hline TOTAL & $\mathbf{1 0 0}$ \\
\hline
\end{tabular}

Fuente: elaboración propia.

${ }_{50}$ SENA. Herramienta de diagnóstico en alianza con el sistema nacional de atención y reparación integral a las víctimas (SNARIV). 2020. 
A continuación, se dará una breve descripción de los indicadores, mediante las siguientes figuras:

Figura 2 - Aspectos de operación

\begin{tabular}{|c|c|c|c|c|c|}
\hline ASPECTOS DE OPERACIÓN & $\begin{array}{c}\text { Cumple totalmente }=2 \\
\text { Cumple parcialmente }=1 \\
\text { No cumple }=0\end{array}$ & \begin{tabular}{|c} 
PUNTAJE TOTAL \\
$15 \%$ \\
\end{tabular} & \% PARTICIPAC. & \% CUMPLIM. & OBSERVACIONES CUALITATIVAS (HALLAZGOS) \\
\hline \begin{tabular}{|l} 
Cuenta con conocimientos técnicos en el área de la unidad productiva \\
\end{tabular} & 0 & \multirow{8}{*}{$0,0 \%$} & $20,0 \%$ & $0,0 \%$ & \\
\hline Cuenta con instalaciones para el funcionamiento de su unidad productiva & 0 & & $20,0 \%$ & $0,0 \%$ & \\
\hline $\begin{array}{l}\text { Cuenta con las maquinaria, herramientas o tecnología necesaria para el desarrollo de su } \\
\text { unidad productiva }\end{array}$ & 0 & & $15,0 \%$ & $0,0 \%$ & \\
\hline $\begin{array}{l}\text { Tiene identificada su capacidad de producción o prestación del servicio } \\
\end{array}$ & 0 & & $10,0 \%$ & $0,0 \%$ & \\
\hline Cuenta con fichas técnicas de los productos & 0 & & $5,0 \%$ & $0,0 \%$ & \\
\hline Cuenta con proveedores formales para la fabricación de sus productos & 0 & & $10,0 \%$ & $0,0 \%$ & \\
\hline \begin{tabular}{|l} 
Aplica normas de seguridad en el trabajo e higiene en su unidad productiva \\
\end{tabular} & 0 & & $15,0 \%$ & $0,0 \%$ & \\
\hline Aplica políticas ambientales en su unidad productiva & 0 & & $5,0 \%$ & $0,0 \%$ & \\
\hline
\end{tabular}

Fuente: el Sena (2020)

En los aspectos de operación y con un peso del 15\%, se disgregan factores como conocimientos técnicos, capacidad de producción, normas de seguridad en el trabajo y demás elementos relevantes a considerar.

Figura 3 - Aspectos Administrativos

\begin{tabular}{|c|c|c|c|c|c|}
\hline ASPECTOS_ADMINISTRATIVOS & \begin{tabular}{|c|} 
Cumple totalmente $=2$ \\
Cumple parcialmente $=1$ \\
No cumple $=0$
\end{tabular} & \begin{tabular}{|c|} 
PUNTAJE TOTAL \\
$15 \%$
\end{tabular} & \% PARTICIPAC. & \% CUMPLIM. & OBSERVACIONES CUALITATIVAS (HALLAZGOS) \\
\hline Cuenta con metas y objetivos. & 2 & \multirow{6}{*}{$100,0 \%$} & $20,0 \%$ & $20,0 \%$ & \\
\hline Cuenta con un plan de negocio formulado que direccione su operación & 2 & & $20,0 \%$ & $20,0 \%$ & \\
\hline Su unidad productiva genera mas de un empleo & 2 & & $5,0 \%$ & $5,0 \%$ & \\
\hline Aplica conocimientos básicos del servicio al cliente en su negocio & 2 & & $20,0 \%$ & $20,0 \%$ & \\
\hline Identifica las necesidades de fortalecer sus competencias para el manejo del negocio & 2 & & $15,0 \%$ & $15,0 \%$ & \\
\hline tiene identificado las debilidades $\mathrm{y}$ fortalezas de su negocio & 2 & & $20,0 \%$ & $20,0 \%$ & \\
\hline
\end{tabular}

Fuente: el Sena (2020)

En los aspectos administrativos y con un peso del 15\%, se consideran factores como definición de metas y objetivos, generación de empleo, entre otros importantes dentro de la administración de un negocio.

Figura 4 - Aspectos de Mercado

\begin{tabular}{|c|c|c|c|c|c|}
\hline ASPECTOS_DE_MERCADO & $\begin{array}{c}\begin{array}{c}\text { Cumple totalmente }=2 \\
\text { Cumple parcialmente }=1 \\
\text { No cumple }=0\end{array} \\
\end{array}$ & \begin{tabular}{|c} 
PUNTAJE TOTAL \\
$\mathbf{2 0 \%}$
\end{tabular} & \% PARTICIPAC. & \% CUMPLIM. & OBSERVACIONES CUALITATIVAS (HALLAZGOS) \\
\hline Cuenta su negocio con algún tipo de publicidad & 2 & \multirow{7}{*}{$100,0 \%$} & $20,0 \%$ & $20,0 \%$ & \\
\hline \begin{tabular}{|l|} 
Tiene identificada sus clientes potenciales \\
\end{tabular} & 2 & & $10,0 \%$ & $10,0 \%$ & \\
\hline Identifica su competencia en el mercado. & 2 & & $10,0 \%$ & $10,0 \%$ & \\
\hline Cuenta con un catálogo de productos o de servicios & 2 & & $20,0 \%$ & $20,0 \%$ & \\
\hline Su producto o servicio cuenta con algún componente innovador & 2 & & $15,0 \%$ & $15,0 \%$ & \\
\hline \begin{tabular}{|l|} 
Cuenta con estrategias de promoción de su producto \\
\end{tabular} & 2 & & $15,0 \%$ & $15,0 \%$ & \\
\hline Cuenta con una proyección de ventas & 2 & & $10,0 \%$ & $10,0 \%$ & \\
\hline
\end{tabular}

Fuente: el Sena (2020)

En los aspectos de mercado y con un peso del 20\%, se consideran factores de publicidad, innovación, estrategias de promoción y demás variables importantes.

Figura 5 - Aspectos Contables y Financieros

\begin{tabular}{|c|c|c|c|c|c|}
\hline ASPECTOS_CONTABLES_Y_FINANCIEROS & $\begin{array}{c}\text { Cumple totalmente }=2 \\
\text { Cumple parcialmente }=1 \\
\text { No cumple }=0\end{array}$ & \begin{tabular}{|c} 
PUNTAJE TOTAL \\
$20 \%$ \\
\end{tabular} & \% PARTICIPAC. & \% CUMPLIM. & OBSERVACIONES CUALITATIVAS (HALLAZGOS) \\
\hline \begin{tabular}{|l|} 
Cuenta con registro de ingresos y gastos \\
\end{tabular} & 2 & \multirow{5}{*}{$100,0 \%$} & $25,0 \%$ & $25,0 \%$ & \\
\hline Tiene definido los costos y gastos para el funcionamiento de su negocio & 2 & & $25,0 \%$ & $25,0 \%$ & \\
\hline La ventas que realiza le permiten que su negocio sea sostenible & 2 & & $30,0 \%$ & $30,0 \%$ & \\
\hline Tiene definido inventarios de materia primas e insumos & 2 & & $10,0 \%$ & $10,0 \%$ & \\
\hline Tiene definido inventarios de producto terminado & 2 & & $10,0 \%$ & $10,0 \%$ & \\
\hline
\end{tabular}

Fuente: el Sena (2020)

En los aspectos contables y financieros y con un peso del 20\%, se consideran factores como el registro de ingresos, gastos y costos, sostenibilidad del negocio, entre otros.

\section{Figura 6 - Fuentes de Financiación}

\begin{tabular}{|l|c|c|c|c|c|}
\hline \multicolumn{1}{|c|}{ FUENTES_DE_FINANCIACION } & $\begin{array}{c}\text { Cumple totalmente= } \\
\text { Cumple parcialmente= } \\
\text { No cumple } \mathbf{0}\end{array}$ & $\begin{array}{c}\text { PUNTAJE TOTAL } \\
\mathbf{3 0 \%}\end{array}$ & \% PARTICIPAC. & \% CUMPLIM. & OBSERVACIONES CUALITATIVAS (HALLAZGOS) \\
\hline Su negocio fue implementado con recursos propios & 2 & $\mathbf{1 0 0 , 0 \%}$ & $30,0 \%$ & $30,0 \%$ & \\
\hline Su negocio fue implementado con otras fuentes de financiación & 2 & $70,0 \%$ & $70,0 \%$ & \\
\hline
\end{tabular}

Fuente: el Sena (2020)

En el aspecto de fuentes de financiación y con un peso del 30\%, se tiene en cuenta la implementación del negocio con recursos propios u otras fuentes de financiación. 
Figura 7 - Resultado Ponderado

\begin{tabular}{|l|c|c|}
\hline \multicolumn{1}{|c|}{ TOTAL GENERAL } & $85,0 \%$ & \\
\hline \multicolumn{1}{|c|}{ PROMEDIO RESULTADO } & $80,0 \%$ & \\
\hline EN PELIGRO & & \\
\hline INDEFENSA & & \\
\hline FORTALECIDA & & \\
\hline
\end{tabular}

Fuente: el Sena (2020)

Una vez realizado el diagnóstico, se obtiene el total general y el promedio del resultado teniendo en cuenta los pesos porcentuales en cada aspecto. De acuerdo a ese resultado, la unidad productiva, se considera en peligro, indefensa o fortalecida.

\subsection{Matriz estado del arte de unidades productivas}

Como complemento a la herramienta aplicada, se desarrolla una matriz con el fin de identificar el estado del arte de las unidades productivas que efectivamente se lograron contactar y realizar la aplicación de dicha herramienta. En la primera parte se identifica la fecha de reporte, regional, vigencia (2017, 2018 o 2019), nombre del gestor quien aplica la encuesta y datos básicos del emprendedor que son reservados ya que son víctimas del conflicto armado:

Figura 8 - Matriz estado del arte de unidades productivas

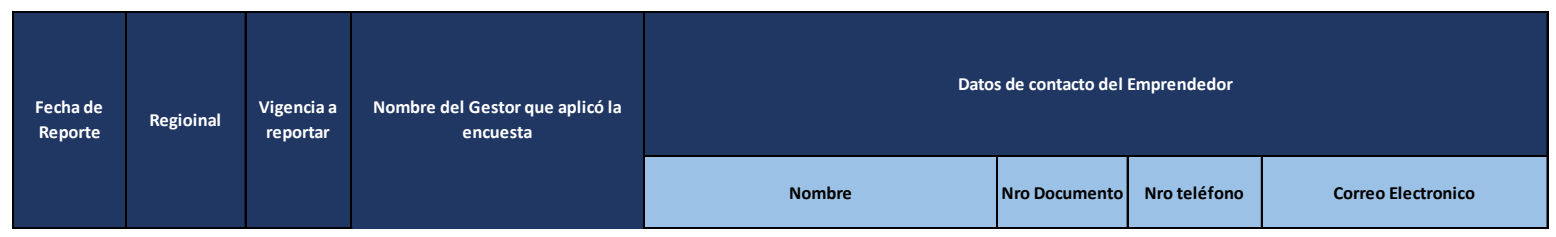

Fuente: el Sena (2020)

En la siguiente parte, se identifica el estado (indefensa, en peligro o fortalecida), los aspectos que requiere el fortalecimiento de acuerdo a los indicadores y las necesidades de formación identificadas:

Figura 9 - Aspectos a fortalecer la unidad productiva

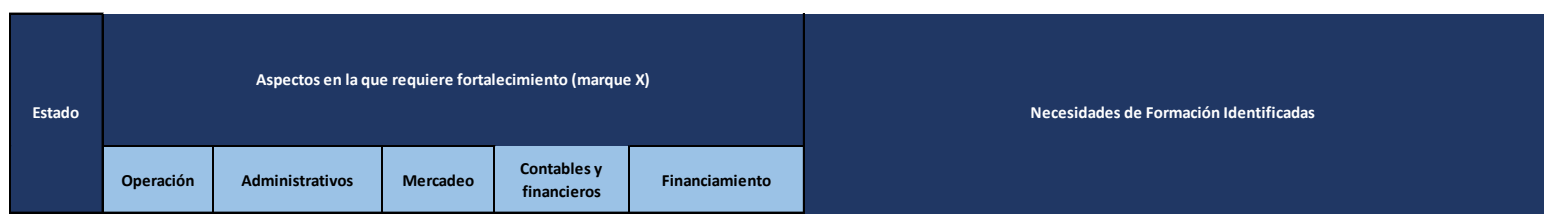

Fuente: el Sena (2020)

\subsection{Apéndice}

A continuación, se describen los resultados de la aplicación de la herramienta utilizada y la matriz del estado del arte de las unidades productivas.

\subsubsection{Aplicación de la herramienta de diagnóstico}

La herramienta fue aplicada a las unidades productivas, caracterizadas por los diferentes emprendimientos del Valle del Cauca, la que arrojó el siguiente resultado: 
Gráfico 2 - Estado de las Unidades Productivas

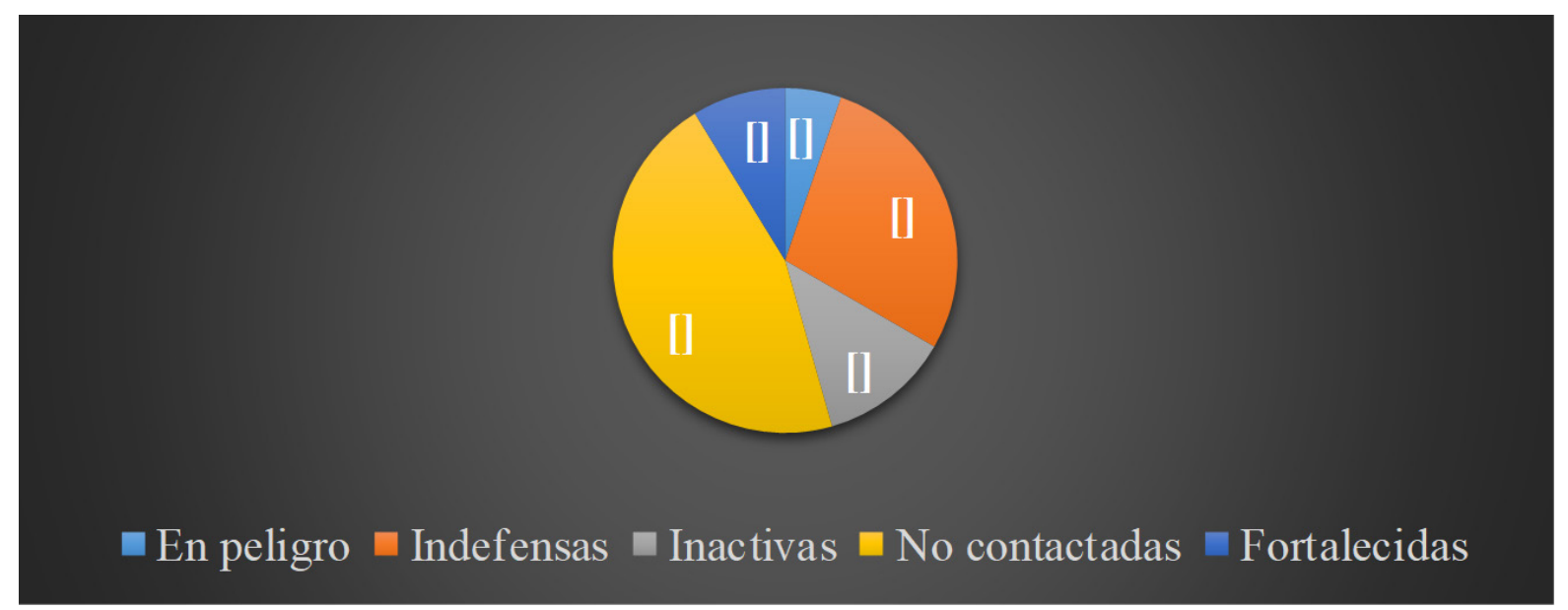

Fuente: elaboración propia.

Del total de las unidades productivas, 3 equivalente al 5,26\%, se encontraban en peligro, 16 equivalente al $28,07 \%$ se encontraban indefensas, 7 equivalente al 12,28\% se encontraban inactivas, 26 equivalente al $45,62 \%$ no pudieron ser contactadas y 5 equivalente al $8,77 \%$ se encontraban fortalecidas.

\subsubsection{Estado del arte de las unidades productivas}

En este aspecto, se hace una breve descripción del resultado que arrojó la aplicación de la herramienta y el estado de las unidades productivas.

Gráfico 3 - Unidades productivas atendidas 2017-2019

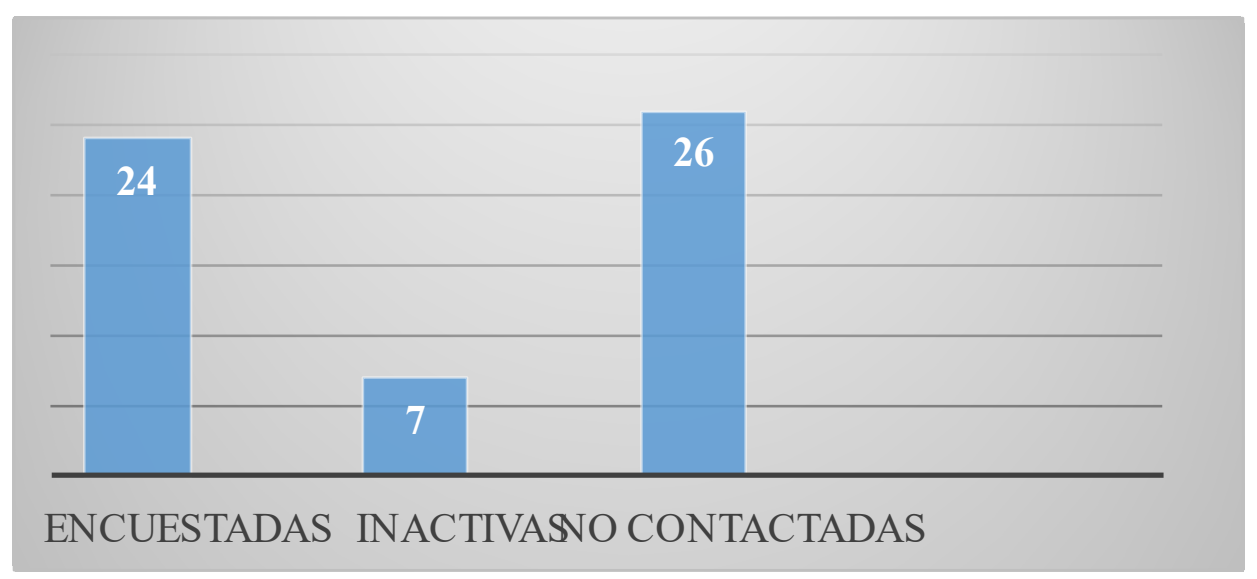

Fuente: elaboración propia.

De las 57 unidades productivas atendidas en el período 2017-2019, se logró la aplicación de la herramienta a 24 , que representan el $42 \%$ del total, 7 se encontraban inactivas, que representan el $12,28 \%$ del total y 26 no pudieron ser contactas, que representan el 45,61\% del total.

\subsubsection{Comprobación de hipótesis}

De acuerdo al informe de Confecámaras en el 2016, sólo el 40\% de las empresas creadas sobreviven en el quinto año de creación, mientras que en el estudio realizado se demuestra que el 8,77\% se encontraban 
fortalecidas ${ }^{51}$, lo que hace suponer que existen factores determinantes que aún hacen falta consolidar de tal manera que permitan al ecosistema de emprendimiento brindar una articulación que contribuya a la puesta en marcha de las ideas de negocios y fortalecimiento de empresas generadas por las víctimas del conflicto armado y que sus ingresos sean sostenibles para su reestabilización socioeconómica. En este sentido, se puede comprobar la siguiente hipótesis:

La falta de articulación interinstitucional dificulta que los emprendedores, víctimas del conflicto armado, tengan una fuente de generación de ingresos sostenible en el tiempo.

Según los resultados de las gráficas presentadas en el apéndice, se puede percibir que pueden influir diferentes factores que limitan la puesta en marcha, crecimiento y consolidación de ideas emprendedoras, debido a que prevalecen los emprendimientos por necesidad y no por oportunidad, especialmente en el sector de consumo donde no se genera mucho impacto en la innovación, transmisión de conocimiento y creación de nuevos empleos ${ }^{52}$.

De acuerdo al estudio realizado se identificaron que de las unidades productivas 3 se encontraban en peligro, 16 indefensas y 7 inactivas para un total de 26 en riesgo del total de las 57, lo que equivale al 45,61\% que no tienen una sostenibilidad continua en el tiempo. Además, otras 26 unidades productivas que representa el 45,62\%, no pudieron ser contactadas por lo que no permitió identificar su estado al momento de la aplicación de la herramienta de diagnóstico. Por tanto, se puede suponer que, por diversos factores, los emprendedores que son población víctima del conflicto armado no generan negocios que sean una solución al componente de generación de ingresos dentro de su proceso de reparación, comprobando la siguiente hipótesis:

La población víctima del conflicto armado que decide emprender al igual que otro tipo de población, en el momento de desarrollar su actividad, no logra un equilibrio económico.

\subsubsection{Discusiones}

Después del estudio realizado sobre el emprendimiento como fuente de generación de ingresos para las víctimas del conflicto armado y teniendo en cuenta la actividad experimentada en la gestión realizada en el campo de asesoría y seguimiento a los programas que realizan las entidades pertenecientes al SNARIV, se puede revisar la sinergia interinstitucional que se presenta y que puede inferir en propuestas de mejoramiento que redunde en el beneficio de la población sujeto de reparación con el fin de lograr su reestabilización socioeconómica.

\section{Conclusiones}

La ley 1448 de 2011 define los componentes de reparación integral para las víctimas del conflicto armado y dentro del aspecto de generación de ingresos se establece la vinculación laboral y el emprendimiento. En cuanto al emprendimiento y durante el período de 2017-2019, en el Valle del Cauca se atendieron iniciativas de negocio como respuesta a la necesidad de generar fuentes de ingresos para el sostenimiento de las víctimas que de manera individual o colectiva se encuentran en búsqueda de soluciones para cubrir sus necesidades básicas.

\footnotetext{
51 CONFECAMARAS. Nacimiento y Supervivencia de las empresas en Colombia. 2016. Disponible en: https://www.confecamaras.org.co/ phocadownload/Cuadernos_de_analisis_economico/Cuaderno_de_An\%D0\%B0lisis_Economico_N_11.pdf.

52 GEM. Global Entrepreneurship Monitor 2017: Global Report. Disponible en: https://www.gemconsortium.org/report/gem2017-2018-global-report.
} 
La literatura analizada, a través de la implementación de fuentes secundarias, en las que se incluyeron bases de datos como: Science Direct, Scopus, Google Scholar e informes académicos, permitieron ubicar dentro del contexto de hallazgos realizados por otros autores, lo cual facilitó la interpretación de los resultados en coherencia y relación de la aplicación de la Ley de Víctimas y el componente de reparación sobre generación de ingresos, incluyendo al emprendimiento como uno de los ejes claves en este aspecto.

La interpretación generada a partir del meta-análisis generó insumos de variables incluidas en la herramienta de diagnóstico empresarial y la matriz del estado del arte de las unidades productivas, permitiendo así llegar a información relevante, en el que se evidenció que, un porcentaje muy bajo de las empresas que hicieron parte del estudio, al quinto año se encontraban fortalecidas. De igual forma, se identificó que los emprendimientos prevalecen por necesidad y no por oportunidad, y esta situación se pudo ver reflejada al momento en el que los emprendedores generan poca inversión en aspectos como innovación y transmisión del conocimiento, ocasionado así limitaciones en cuanto a la puesta en marcha, crecimiento y consolidación de sus ideas emprendedoras. Lo anterior, permitió la interpretación y comprobación de las hipótesis planteadas.

De igual forma, se hace necesario profundizar en el tema de la Ley 1448 y sus componentes de reparación como futuras línea de investigación y especialmente en el aspecto de generación de ingresos, identificando estrategias de seguimiento y fortalecimiento de las unidades productivas de la población víctima del conflicto armado.

\section{Referencias}

AMORÓS, José Ennesto; FERNÁNDEZ, Crsitóbal; TAPIA, Juan. Quantifying the relationship between entrepreneurship and competitiveness development stages in Latin America. International Entrepreneurship and Management Journal, v. 8, p. 249-270, 2012. Disponible en: https://link.springer.com/article/10.1007/ s11365-010-0165-9.

ARÉVALO, Estefania; SOTOMAYOR, Carolina. La restitución de tierras consagrada en la Ley 1448 de 2011, a la luz de la teoría neoconstitucionalista. Revista Academía y Derecho, v. 7, n. 13, p. 91-118, 2016. Disponible en: http://190.143.117.169/ojs/index.php/derecho/article/view/124.

BENZ, Matthias. Entrepreneurship as a non-profit seeking activity. International Entrepreneurship and Management Journal, v. 5, p. 23-44, 2009. Disponible en: https://link.springer.com/article/10.1007/s11365-0060031-y.

BERTRANOU, Julián. El seguimiento y la evaluación de políticas públicas. Modelos disponibles para producir conocimiento y mejorar el desempeño de las intervenciones públicas. Millcayac Revista Digital de Ciencias Sociales, v. 6, n. 10, p. 151-188, 2019. Disponible en: https://revistas.uncu.edu.ar/ojs3/index.php/millca-digital/article/view/1730.

BLANCO, Ismael; GOMÀ, Ricard. La crisis del modelode gobierno tradicional: reflexiones en torno a la governance participativa y de proximidad. Gestión y Política Pública, v. 12, n. 1, p. 5-42, 2003. Disponible en: https://www.redalyc.org/pdf/133/13312101.pdf.

BRAVO GARCÍA, Saulo. Análisis de las características de un emprendedor en proceso de incubación y no incubados. Sotavento M.B.A., v. 21, p. 40-48, ene./jun. 2013. Disponible en: https://revistas.uexternado.edu. co/index.php/sotavento/article/view/3435/3122.

BUENO SUÁREZ, Carlos; OSUNA LLANEZA, José Luis. Reflexiones epistemológicas y metodológicas para la evaluación de políticas públicas. Andamios: Revista de Investigación Social, v. 10, n. 21, p. 95-117, ene./abr. 2013. Disponible en: https://www.redalyc.org/pdf/628/62828836005.pdf. 
CAMPBELL, Siobhan; BENITA, Siobhan; COATES, Elizabeth; DAVIES, Phil; PENN, Gemma. Analysis for policy: evidence-based policy in practice. London: HM Treasury, 2007. Disponible en: https://www.srhr-ask-us.org/publication/analysis-policy-evidence-based-policy-practice/.

CANCINO, Christian; BONILLA, Claudia. Financiamiento público al emprendimiento chileno: un análisis chileno. Trend Management, p. 156-161, 2011.

CASTELAO CARUANA, María Eugenia. Las políticas públicas y su visión de la economía social y solidaria en Argentina. Revista Mexicana de Ciencias Políticas y Sociales, v. 61, n. 227, 2016. Disponible en: http://www. revistas.unam.mx/index.php/rmcpys/article/view/49598.

CENTRO DE MEMORIA HISTÓRICA. Los orígenes, las dinámicas y el crecimiento del conflicto armado. In: ;Basta ya! Colombia: Memorias de Guerra y Dignidad: informe general grupo de memoria histórica. 2016. p. 111-194. Disponible en: http://centrodememoriahistorica.gov.co/descargas/informes2013/bastaYa/capitulos/basta-ya-cap2_110-195.pdf.

COLOMBIA. Mininterior. Conpes 3712 de 2011: plan de financiación para la sostenibilidad de la Ley 1448 de 2011. 1 de diciembre 2011. Disponible en: https:/ /www.mininterior.gov.co/content/conpes-3712-de-2011.

COLOMBIA. Minjusticia. Decreto 4800 de 2011: por el cual se reglamenta la Ley 1448 de 2011 y se dictan otras disposiciones. 20 de diciembre 2011. Disponible en: https://www.unidadvictimas.gov.co/es/decreto-4800-de-2011/13108.

COLOMBIA. Mintrabajo. Educándonos para la paそ: 2016. Disponible en: https://www.mintrabajo.gov.co/ el-ministerio/reparacion-integral-victimas/formacion-para-el-trabajo-y-vocacional/educandonos-para-la-paz.

COLOMBIA. Mintrabajo. Emprendiendo retornos. 2017. Disponible en: https://www.mintrabajo.gov.co/el-ministerio/reparacion-integral-victimas/emprendimiento/emprendiendo-retornos.

COLOMBIA. Mintrabajo. Grupo Interno de Trabajo Para las Victimas y la Equidad Laboral con Enfoque de Género: reparación para las víctimas del conflicto armado en Colombia. S.f. Disponible en: http://www.mintrabajo. gov.co/web/guest/el-ministerio/victimas-y-equidad-laboral-con-enfoque-de-genero?inheritRedirect=true.

COLOMBIA. Mintrabajo. Orientados hacia la paz: 2018. Disponible en: https://www.mintrabajo.gov.co/el-ministerio/reparacion-integral-victimas/formacion-para-el-trabajo-y-vocacional/orientados-hacia-la-paz.

COLOMBIA. Mintrabajo. TransFórmate. 2013. Disponible en: https://www.mintrabajo.gov.co/el-ministerio/reparacion-integral-victimas/formacion-para-el-trabajo-y-vocacional/transformate.

CONFECAMARAS. Nacimiento y Supervivencia de las empresas en Colombia. 2016. Disponible en: https://www.confecamaras.org.co/phocadownload/Cuadernos_de_analisis_economico/Cuaderno_de_ An\%D0\%B0lisis_Economico_N_11.pdf.

CONGRESO DE COLOMBIA. Ley 448 de 2011: Artículo 51 y 130, de 10 de junio, por la cual se dictan medidas de atención, asistencia y reparación integral a las víctimas del conflicto armado interno y se dictan otras disposiciones. 10 de junio de 2011. Disponible en: https://www.unidadvictimas.gov.co/es/ley-1448de-2011/13653.

CONGRESO DE COLOMBIA. Ley 975 de 2005: por la cual se dictan disposiciones para la reincorporación de miembros de grupos armados organizados al margen de la ley, que contribuyan de manera efectiva a la consecución de la paz nacional y se dictan otras disposiciones para acuerdos humanitarios. 25 de julio de 2005. Disponible en: https://www.unidadvictimas.gov.co/es/ley-975-del-25-de-julio-de-2005/14849.

DEVINS, D. Enterprise in deprived areas: what role for start-ups?. International Journal of Entrepreneurship and Small Business, v. 8, p. 486-498, 2009. Disponible en: https://www.researchgate.net/publication/260338809_ 
Is_Informal_Sector_Entrepreneurship_Necessity-_or_Opportunity-driven_Some_Lessons_from_Urban_ Brazil.

DOANHA, Duong Cong; TRANG, Tran Van. Entrepreneurial self-efficacy and intention among vietnamese students: a meta-analytic path analysis based on the theory of planned behavior. Management Science Letters, v. 9, p. 1847-1862, 2019. Disponible en: https://www.growingscience.com/msl/Vol9/msl_2019_154.pdf.

DUARTE, Tito; RUIZ, Myriam. Emprendimiento, una opción para el desarrollo. Scientia Et Technica, v. 15, n. 43, p. 326-331, 2009. Disponible: https://www.redalyc.org/pdf/849/84917310058.pdf.

FLORES, Pedro. El enfoque de la política basado en la evidencia: análisis de su utilidad para la educación de México. Revista mexicana de investigación educativa, v. 18, n. 56, p. 265-290, 2013. Disponible en: http://www. scielo.org.mx/scielo.php?pid=S1405-66662013000100012\&script=sci_arttext.

FRANCISKOVIC, Jubitza. Retos de la gestión pública: presupuesto por resultados y rendición de cuentas. Journal of Economics, Financeand Administrative Science, v. 18, p. 28-32, 2013. Disponible en: https://www.sciencedirect.com/science/article/pii/S2077188613700283.

GALINDO-MARTÍNA, Miguel Ángel; MÉNDEZ-PICAZO, María Teresa; CASTAÑO-MARTÍNEZ, María Soledad. Crecimiento, progreso económico y emprendimiento. Journal of Innovation \& Knowledge, v. 1, p. 62-68, 2016. Disponible en: https://www.econstor.eu/bitstream/10419/190693/1/1023020734.pdf.

GEM. Global Entrepreneurship Monitor 2014: Global Report. Disponible en: https://www.gemconsortium. org/report/gem-2014-global-report.

GEM. Global Entrepreneurship Monitor 2017: Global Report. Disponible en: https://www.gemconsortium. org/report/gem-2017-2018-global-report.

GIACOMIN, Olivier; JANSSEN, Frank; GUYOT, Jean-Luc; LOHEST, Olivier. Opportunity and/ or necessity entrepreneurship?: the impact of the socio-economic characteristics of entrepreneurs. Munich: MPRA, 2011. Disponible en: https://mpra.ub.uni-muenchen.de/29506/2/MPRA_paper_29506.pdf.

GONZÁLEZ, Julio. Verdad, justicia, paz y reparación en la mitología penal: a propósito de la ley 975 de 2005. Estudios politicos, Medellín, n. 27, p. 45-63, 2005. Disponible en: https://bibliotecadigital.udea.edu.co/ handle/10495/8718.

JIMÉNEZ-SILVA, Walter; LARREA-ALTAMIRANO, Janeth; NAVARRETE-FONSECA, Mario; CASTRO-AYALA, Edisson. Emprendimientos innovadores a partir de competencias cognitivas en estudiantes universitarios. Revista venezolana de gerencia, v. 24, n. 85, 2019. Disponible en: https://www.redalyc.org/articulo.oa?id $=29058864004$.

KITZMUELLER, Markus; SHIMSHACK, Jay. Economic Perspectives on Corporate Social Responsibility. Journal of Economic Literature, v. 50, n. 1, p. 51-84, 2012. Disponible en: doi:10.1257/jel.50.1.51.

LARROULET, Cristián; RAMÍREZ, Macarena. Emprendimiento: factor clave para la nueva etapa de Chile. In: DURÁN, P. (ed.). Emprendimiento e innovación en Chile. Santiago: Facultad de Economía y Negocios, Universidad del Desarrollo, 2008. p. 15-38. Disponible en: https://www.academia.edu/14148885/ Emprendimiento_e_Innovaci\%C3\%B3n_en_Chile_Una_Tarea_Pendiente.

MONDRAGÓN, Jaione. La evaluación de los programas públicos: objeto, contenido y aplicación de diferentes instrumentos para la evaluación. In: BAÑÓN, R. (ed.). La evaluación de la acción y de las políticas públicas. Díaz de Santos, 2003. p. 3-12. Disponible en: https://books.google.com.co/books?hl=en\&lr=\&id=9QE4SRJV-HUC\&oi=fnd\&pg=PR9\&dq=buena + aplicaci $\% \mathrm{C} 3 \% \mathrm{~B} 3 \mathrm{n}+$ de + las + pol $\% \mathrm{C} 3 \%$ ADticas $+\mathrm{p} \% \mathrm{C} 3 \% \mathrm{BAblic}$ as, + se + requiere + un + riguroso + seguimiento + que + eval $\% \mathrm{C} 3 \% \mathrm{BAe}+$ su + eficiencia + mientras $+\& o t s=\mathrm{Meh}$ 7V_ZE-3\&sig=aQbymz9qujqViiE0rV62_N6ALFI\&redir_esc $=y \#_{\mathrm{v}}=$ onepage\&q\&f=false. 
NIÑO, César. Breve historia del conflicto armado en Colombia. Revista de pazy conflictos, v. 10, n. 1, p. 327330, 2017. Disponible en: https://www.redalyc.org/pdf/2050/205052042015.pdf.

OCA ROJAS, Y. M. M. Perspectivas del emprendimiento social y redes socioproductivas de pequeños productores en Venezuela. Revista de ciencias sociales, v. 26, n. 1, p. 300-312, ene./mar. 2020. Disponible en: https://produccioncientificaluz.org/index.php/rcs/article/view/31326/32376.

OEI. Programa Colombia Emprende. 2020. Disponible en: https://oei.int/oficinas/colombia/noticias/pre-inscripcion-fase-i-del-programa-colombia-emprende.

OIT. Proyecto el futuro de los jóvenes. 2019. Disponible en: https://www.ilo.org/lima/programas-y-proyectos/ WCMS_731346/lang--es/index.htm.

OLAYA GOEZ, Paula Andrea. Proceso de Individuación y Subjetivación de Cinco Mujeres que llegan a Cali en medio del conflicto armado. 2014. Disertación (Maestría en Sociología) - Facultad de Ciencias Sociales y Económicas, Universidad del Valle, Cali, 2014. Disponible en: http://bibliotecadigital.univalle.edu.co/ bitstream/10893/7585/1/0508699-p-14-ms.pdf.

PINILLA, Jaime; GARCÍA-ALTÉS, Anna. La evaluación de políticas públicas: Informe SESPAS 2010. Gaceta sanitária, v. 24, p. 114-119, dic. 2010. Disponible en: https://www.sciencedirect.com/science/article/ pii/S021391111000169X.

PROGRAMA DE LAS NACIONES UNIDAS PARA EL DESARROLLO. Emprendimiento y empleabilidad para familias rurales víctimas del conflicto armado: Desarrollo Incluyente Rural para familias víctimas del conflicto. 2020. Disponible en: https://www.co.undp.org/content/colombia/es/home/projects/emprendimiento-y-empleabilidad-para-familias-rurales-victimas-de.html.

REYNOLDS, Paul D.; BYGRAVE, William D.; AUTIO, Erkko; COX, Larry W.; HAY, Michael. Global entrepreneurship Monitor: 2002 executive report. Kansas City: Kauffman Center for Entrepreneurial Leadership, 2002. Disponible en: http://www.esbri.se/gemglobalreport_2002.pdf.

RODRIGUEZ TOVAR, Sergio Enrique. Transferencia y acceso a la tierra en contextos de violencia: análisis empírico para el municipio de Guadalajara de Buga, 2001-2013. 2016. Disertación (Maestría en Economía Aplicada) - Facultad de Ciencias Sociales y Económicas, Universidad del Valle, Cali, 2016. Disponible en: http:// bibliotecadigital.univalle.edu.co/bitstream/10893/9897/1/0534285-ME-2016-2.pdf.

SENA. Herramienta de diagnóstico en alianza con el sistema nacional de atención y reparación integral a las víctimas (SNARIV). 2020.

SERRANO GÓMEZ, Rocío; ACEVEDO PRADA, Milena. Reflexiones en torno a la aplicación de la Ley 1448 de 2011 y la restitución de tierras en Colombia. Revista de la facultad de derecho y ciencias politicas, Medellín, v. 43, n. 118, p. 533-566, ene./jun. 2013. Disponible en: http://www.scielo.org.co/pdf/rfdcp/v43n119/ v43n119a03.pdf.

SNARIV. Entidades que conforman el sistema nacional de atención y reparación integral a las víctimas. S.f. Disponible en: http://www.portalsnariv.gov.co/node/1000\#: :text=Departamento $\% 20$ Nacional $\% 20 \mathrm{de} \% 20$ Planeaci $\%$ C3\%B3n $\% 20 \% 2 D D N P$,fng.gov.co $\% 2$ FES.

TAMAYO SÁEZ, Manuel. El análisis de las políticas públicas. In: BAÑÓN, Rafael; CARRILLO, Ernesto. La nueva administración pública. Madrid: Alianza Editorial, 1997. p. 281-311. Disponible en: https://www. fundacionhenrydunant.org/images/stories/biblioteca/Politicas-Publicas/tamayo_analisis_de_polit_publ. tif.pdf.

UNIDAD PARA LAS VÍCTIMAS. Fondo para la reparación s las víctimas. S.f. Disponible en: http://www. unidadvictimas.gov.co/es/fondo-para-la-reparaci\%C3\%B3n-las-v\%C3\%ADctimas/80. 
VARGAS ARÉBALO, Cidar. Análisis de las políticas públicas. Perspectivas, v. 19 p. 127-136, ene./jun. 2007. Disponible en: https://www.redalyc.org/pdf/4259/425942453011.pdf.

ZARAMA VÁZQUES, Ernesto. Generación de ingresos para la población desplazada en Colombia: perspectivas desde abajo. Santiago de Chile, 2009. Disponible en: https://repositorio.cepal.org/bitstream/handle/11362/6158/1/S0900694_es.pdf. 
Para publicar na revista Brasileira de Políticas Públicas, acesse o endereço eletrônico www.rbpp.uniceub.br

Observe as normas de publicação, para facilitar e agilizar o trabalho de edição. 